\title{
A Framework for Ranking Hospitals Based on Customer Perception Using Rough Set and Soft Set Techniques
}

\author{
Arati Mohapatro, Research Scholar, Bharathiar University, Coimbatore, India \\ S.K. Mahendran, Assistant Professor, Dept. of Computer Science, Government Arts College, Ooty, India \\ T. K. Das, Associate Professor, School of Information Technology \& Engineering, VIT, Vellore, India
}

\begin{abstract}
Hospital ranking is a cumbersome task, as it involves dealing with a large volume of underlying data. Rankings are usually accomplished by comparing different dimensions of quality and services. Even the quality care measurement of a hospital is multi-dimensional: It includes the experience of both clinical care and patient care. In this research, however, the authors focus on ratings based only on customer perception. A framework which consists of two stages - Stage I and Stage II-is designed. In the first stage, the model uses a rough set in a fuzzy approximation space (RSFAS) technique to classify the data; whereas in the second stage, a fuzzy soft set (FSS) technique is employed to generate the rating score. The model is employed for comparing USA hospitals by region using annual HCAHPS survey data. This article shows how ranking of the healthcare institutions can be carried out using the RSFAS (rough set in a fuzzy approximation space) and fuzzy soft set techniques.
\end{abstract}

\section{KEYWORDS}

Decision making, Fuzzy soft set, Hospital rating, Rough set on fuzzy approximation space, Service quality

\section{INTRODUCTION}

The choice of hospital is very critical for a family - particularly if any family members are facing a serious or complex health problem. To select a best choice from among an array of options is an arduous task. This process becomes even more strenuous when the evaluation criteria are vague or qualitative and when the objectives vary in importance and scope. Additionally, the types of healthcare providers, their functionality, the specialists involved, and the facilities provided are distinct. Hence, there must be a decision tool which would augment the task of searching hospitals when needed. In hospital ranking, healthcare providers and medical centres are assessed by speciality-i.e., cardiology, cancer, ENT, urology, diabetes, neurology, pulmonology, nephrology, gynaecology, orthopaedic, ophthalmology, gastroenterology, etc. Besides calculating which hospitals provide the finest care for the most serious or complicated medical conditions, there is a need for focusing on those hospitals with a perfect record of common care (which is defined as care involving relatively commonplace conditions and procedures).

It is clear from various readings that better service quality boosts customer satisfaction (Radwin, 2000; Gremler, Gwinner, \& Brown, 2001; Kumar, Smart, Maddern, \& Maull, 2008). The impact of service quality on customer satisfaction has been extensively discussed by many authors (Lee, 2012; 
Bohm, 2013; Chia-Wen, Ting-Hsiang, \& Woodside, 2013; Prabhakar, 2014). Perceived quality of service has a direct influence on satisfaction (Lee, Lee, \& Yoo, 2000; Ladhari, 2009).

Today's patients are taking active role in selecting healthcare providers. Accurate ratings of hospitals are essential - as such measures regard health and well-being. However, there is no agreement between the reports of leading healthcare rating agencies. These agencies agree neither on the top-ranking hospital nor on the bottom-ranking hospital (Rothberg, Morsi, Benjamin, Pekow, \& Lindenauer, 2008). This is due to variations in methods used by the rating systems. Austin et al. (2015) compare the reports of four national rating systems. The finding is that there is a lack of agreement among their ratings. This is because each system has its own rating method; and each system has a different measure of outcomes.

A study by Beukers, Kemp, and Varkevissar (2014) revealed that in a setting where prices do not matter for patients due to health insurance coverage, travel time is most significantly impactful when choosing a hospital, followed by the hospital's quality ratings and wait time. Studies on the ranking of hospitals by evaluating the quality of service in those hospitals have been done in different countries. A few of them are listed below:

- In order to determine the top hospital focusing on excellent service quality, multiple criteria decision making (MCDM) methods-Topsis, Yager's min-max technique, OWA, and compensatory AND methods_-are being employed to rank few a Turkish hospitals (Akdag, Kalayer, Karagoz, Zulfikar, \& Giz, 2014).

- An analysis of hospital service quality in Indonesia is carried out by Handayani, Hidayanto, Sandhyaduhita, Kusian, \& Ayuningtyas (2015). This research study analyzes the dimensions required by the hospital to increase the quality of hospital services. These dimensions are human resources, process, policy, and infrastructure.

- Li et al. (2015) investigate the service quality of hospitals in nine Chinese cities. The SERVQUAL scale method was used to investigate the patient's perception of service quality at hospitals which have outpatient and inpatient facilities.

- Another study to determine service quality in the healthcare industry was conducted by Lupo (2016) in the Sicilian region of Italy. It employs an analytic hierarchy process (AHP) to obtain service quality expectations. This study revealed that service quality improvement should focus on the responsiveness of healthcare staff; the teamwork of staff; the ability of doctors to understand patient needs; self-reliability; and the swiftness of the registration-and-admission procedure.

- Meesala and Paul (2018) studied quality and consumer satisfaction in an Indian context. Their observation reflects reliability, and responsiveness contributes significantly to patient satisfaction as compared to other dimensions such as tangibility, empathy and assurance, and patient satisfaction —which, in turn, are proportional to the patient's loyalty to the hospital.

Most of the work uses the service quality framework known as SERVQUAL to measure the quality of services. (Buyukozkan, Cifci, \& Guleryuz, 2011). The most widely known and discussed scale for measuring service quality is SERVQUAL. It was proposed by Parasuraman, Zeithamal, and Berry (1985). Initially, they identified 10 components of service quality: reliability, responsiveness, competence, access, courtesy, communication, credibility, security, understanding, and tangibles. Then, in their 1988 work, (Parasuraman, Zeithamal, \& Berry, 1988), they limited these components into five dimensions: reliability, assurance, tangibles, empathy, and responsiveness. This scale has been applied in the healthcare field in numerous studies (Dagger, Sweeney, \& Johnson, 2007; Andaleeb, 2001; Bakar, Akgün, \& Al Assaf, 2008; Bowers \& Kiefe, 2002; Dean, 1999; Devebakan, 2005; Devebakan \& Aksarayli, 2003; Lee \& Yom, 2007; Lee, Lee, \& Yoo, 2000; Li, 1997; Ramsaran-Fowdar, 2008; Pakdil \& Harwood, 2005; Wisniewski \& Wisniewski, 2005).

Researchers generally make inferences by employing statistical techniques. This growing tendency gets accented in making efficient use of organisational data through data mining and data warehousing 
(Beynon, Curry, \& Morgan, 2001). Hence there is a need for new data analysis and decision-making techniques. Fuzzy set (Zadeh, 1965), rough set (Pawlak, 1982), and soft set Molodstov, 1999) theories are being established as leading theories for handling uncertainty. However, these theories have their own limitations. The essence of the fuzzy set lies in its membership's functions. Determination of the membership functions are based on intuition and on the situation (Chowdhary \& Acharjya, 2017). So, there is no absolute scale for determining the membership functions. The correct value of membership function always confusing as it is shaded by a lack of information and by a vagueness in the way the information which is included is represented. On the other hand, rough set theory is workable only when an equivalence relation in a universe is defined. However, in real-life data, it is rare to have an equivalence class. Hence, the strict requirement of an equivalence class later on is lessened by De (1999). He introduced the concept of fuzzy proximity relation. This concept, along with that of the rough set (rough set in fuzzy approximation space-RSFAS) technique has helped many authors to make the classification task easier (Das \& Acharjya, 2014).

Soft set theory states that an object can only belong to a parameter if the object fully satisfies the requirement of the parameter. Thus, the parameter value can be either 0 or 1 . However, in many real-life situations, information systems are quantitative rather than qualitative. It indicates that, given a parameter, an object may lie partially rather than fully. This introduced the concept of the fuzzy soft set (FSS).

The rest of the paper is organized as follows: A two-stage information system model is presented in Section 2. In Section 3, the authors discuss the rough set and RSFAS (rough set in a fuzzy approximation space) techniques. Soft set and fuzzy soft set techniques are discussed in Section 4. In Section 5, the authors propose a decision-making model. In Section 6, an empirical study to validate the model is discussed and the result is analyzed in Section 7. The paper is concluded in Section 8.

\section{INFORMATION SYSTEM}

An information system can be viewed as a table known as information table where the rows considered as objects and columns as parameters or attributes (Wu, Yue, Li, \& Adjei, 2004). An information system is defined as a quadruple $I=(U, E, V, f)$ where $U$ is a finite set of objects called the universe, $E$ is a finite nonempty subset of parameters, $V=\bigcup_{a \in E} V_{a}$ is a nonempty set of attribute values and $f: U \rightarrow V$ is an information function.

Let us consider the sample information system given in Table 1 , where, $U=\left\{x_{1}, x_{2}, x_{3}, x_{4}, x_{5}\right\} ;$ $E=\{$ Humidity, Windy, Cloudy, Temperature $\}$. The parameters have a range of values, e.g. $V_{\text {Cloudy }}=\{$ Low, Normal, High $\}$. This is an example of a qualitative system, where all the attribute values are discrete and categorical (qualitative).

On the contrary, the information system shown in Table $2, U=\left\{x_{1}, x_{2}, x_{3}, x_{4}, x_{5}\right\}$ represents a set of candidates and $E=\{$ Height, Weight, Chest $\}$ represents a finite nonempty set of parameters. This information system is a quantitative system since all the parameter values are non-categorical.

\section{ROUGH SET}

Rough set was first put forward and established by Pawlak (1982) to deal with vague and uncertain data. The basic definition of rough sets is based upon the approximation of a set by a pair of sets known as lower and upper approximation (Acharjya \& Das, 2017). Let $U$ be the universe of finite non-empty set of objects. Let $R \subseteq U \times U$ is an equivalence relation on $U$. The equivalence relation $R$ partitions the set $U$ into disjoint classes and it is denoted as $U / R$. Let $X$ be a subset of $U$. Therefore, 
Table 1. A qualitative information system

\begin{tabular}{|l|l|l|l|l|}
\hline \multicolumn{1}{|c|}{ Object } & \multicolumn{1}{|c|}{ Humidity } & \multicolumn{1}{c|}{ Cindy } & \multicolumn{1}{c|}{ Temperature } \\
\hline$x_{1}$ & High & Yes & Normal & Hot \\
\hline$x_{2}$ & Low & No & High & Cool \\
\hline$x_{3}$ & Normal & No & Low & Mild \\
\hline$x_{4}$ & Low & Yes & High & Cool \\
\hline
\end{tabular}

Table 2. Quantitative information system

\begin{tabular}{|l|l|l|l|}
\hline \multicolumn{1}{|c|}{ Object } & \multicolumn{1}{|c|}{ Height } & Weight & Chest \\
\hline$x_{1}$ & 170 & 67 & 80 \\
\hline$x_{2}$ & 165 & 70 & 82 \\
\hline$x_{3}$ & 172 & 66 & 82 \\
\hline$x_{4}$ & 175 & 71 & 78 \\
\hline$x_{5}$ & 182 & 72 & 81 \\
\hline
\end{tabular}

\begin{tabular}{|l|l|l|l|l|}
\hline \multicolumn{1}{|c|}{ Object } & \multicolumn{1}{|c|}{ Humidity } & \multicolumn{1}{c|}{ Windy } & \multicolumn{1}{c|}{ Cloudy } & \multicolumn{1}{c|}{ Temperature } \\
\hline$x_{5}$ & High & No & Low & Hot \\
\hline
\end{tabular}

the target set $X$ can be described by lower and upper approximation as represented in equation (1) and (2) respectively, where $\underline{R} X$ and $\bar{R} X$ are $R$-lower and $R$-upper approximations of $X$ respectively.

$$
\begin{aligned}
& \underline{R} X=\cup\left\{X^{\prime} \in U / R: X^{\prime} \subseteq X\right\} \\
& \bar{R} X=\cup\left\{X^{\prime} \in U / R: X^{\prime} \cap X \neq \phi\right\}
\end{aligned}
$$


Boundary region of the set $X, B N_{R}(X)$, is the objects in $X$ that can be distinguished neither as a member nor as a non-member of $X$ employing the relation $R$. It is denoted as $B N_{R}(X)=\bar{R} X-\underline{R} X$. A set $X$ is said to be definable if $\underline{R} X=\bar{R} X$ and the target set is a crisp set i.e., there is no boundary line objects. Similarly, it is said to be rough if $\underline{R} X \neq \bar{R} X$ or equivalently $B N_{R}(X) \neq \phi$.

Rough set has many applications (Das, Acharjya, \& Patra, 2014; Chowdhary \& Acharjya, 2016). But, it has certain limitations while handling quantitative information system. This is because quantitative attribute values are not exactly indiscernible, however, they are almost indiscernible. To overcome this limitation rough set has extended to rough set on fuzzy approximation space.

\subsection{Rough Set on Fuzzy Approximation Space}

Here, the authors present some of the definitions, notations and results of rough set on fuzzy approximation space (De, 1999; Das, 2016).

Let $U$ be universe of discourse. A fuzzy relation on $U$ is a fuzzy subset of $(U \times U)$. A fuzzy relation $R$ on $U$ is said to be a fuzzy proximity relation if $\mu_{R}(x, x)=1$ for all $x \in U$ and $\mu_{R}(x, y)=\mu_{R}(y, x)$ for all $x, y \in U$. For a given $\alpha \in[0,1]$, the $\alpha$-cut of $R$ is given by $R_{\alpha}=\mu_{R}(x, y) \geq \alpha$. Two elements $x$ and $y$ are said to be $\alpha$ - similar with respect to $R$ if $(x, y) \in R_{\alpha}$ and it is written as $x R_{\alpha} y$. Similarly, two elements $x$ and $y$ are said to be $\alpha$-identical with respect to $R$ if either $x$ is $\alpha$ - similar to $y$ or $x$ is transitively $\alpha$ - similar to $y$ with respect to $R$, i.e., there exists a sequence of elements $\left(u_{1}, u_{2}, u_{3}, \ldots, u_{n}\right)$ in $U$ such that $x R_{\alpha} u_{1}, u_{1} R_{\alpha} u_{2}, u_{2} R_{\alpha} u_{3}, \ldots ., u_{n} R_{\alpha} y$. If $x$ and $y$ are $\alpha$-identical with respect to fuzzy proximity relation $R$, then we write $(x, y) \in R(\alpha)$. It is easy to see that for any $\alpha \in[0,1], R(\alpha)$ is an equivalence relation on $U$. The notation $R_{\alpha}^{*}$ is used to denote the set of equivalence classes generated by the fuzzy proximity for any $\alpha \in[0,1]$. The $R(\alpha)$ equivalence class of an element $x$ in $U$ is denoted by $[x]_{\alpha}$ and the pair $(U, R(\alpha))$ is called fuzzy approximation space.

Let $X \subseteq U$. The rough set on fuzzy approximation space of $X$ in the generalized approximation space $(U, R(\alpha))$ is denoted by $\left(\underline{X}_{\alpha}, \bar{X}_{\alpha}\right)$; being the lower approximation and upper approximation are represented in equation (3) and (4).

$$
\underline{X}_{\alpha}=\bigcup\left\{Y: Y \in R_{\alpha}^{*} \text { and } Y \subseteq X\right\}
$$

$$
\bar{X}_{\alpha}=\bigcup\left\{Y \in R_{\alpha}^{*}: Y \cap X \neq \phi\right\}
$$

The $\alpha$-boundary of $X$ with respect to $R$ is defined as $B N R_{\alpha}(X)=\bar{X}_{\alpha}-\underline{X}_{\alpha}$. The set $X$ is said to be $\alpha$-discernible with respect to $R$ if and only if $\bar{X}_{\alpha}=\underline{X}_{\alpha}$ or $B N R_{\alpha}(X)=\phi$. The set $\mathrm{X}$ is said to be $\alpha$-rough with respect to $R$ if and only if $\bar{X}_{\alpha} \neq \underline{X}_{\alpha}$ or $B N R_{\alpha}(X) \neq \phi$. It is clearly identified that, rough set on fuzzy approximation space reduces to Pawlak's rough sets if $\alpha=1$. 


\section{SOFT SET AND FUZZY SOFT SET}

The theory of soft set (Molodstov, 1999) has been under continuous development for over few decades and a growing number of researchers have shown interest in this area. Soft set is a mathematical tool for dealing with uncertain, fuzzy and not clearly defined objects. Here, we present the fundamental concepts, notations and results on soft set (Molodstov, 1999; Maji et al., 2002) which forms the basis of our proposed decision making model.

Let $U$ be a universal set of objects and $E$ be a set of parameters. Let $P(U)$ denotes the power set of $U$ and $A \subseteq E$. A pair $(F, A)$ is called a soft set over $U$, where $F$ is a mapping given by $F: A \rightarrow P(U)$. In other words, the soft set is a parameterized family of subsets of the universe $U$. For $a \in A, F(a)$ may be considered as the set of $a$-approximate elements of the soft set $(F, A)$. For illustration we present an example as below.

Let $U=\left\{x_{1}, x_{2}, x_{3}, x_{4}, x_{5}, x_{6}\right\}$ be a set of apartments and $E=\left\{\right.$ Expensive $\left(a_{1}\right)$, Swimming pool $\left(a_{2}\right)$, Children's park $\left(a_{3}\right)$, Cheap $\left(a_{4}\right)$, Club house $\left.\left(a_{5}\right)\right\}$ be the set of parameters. Suppose $F($ Expensive $)=\left\{x_{3}, x_{4}\right\} ; \quad F($ swim min gpool $)=\left\{x_{1}, x_{3}, x_{6}\right\} ; \quad F($ Children's park $)=\left\{x_{2}\right.$, $\left.x_{4}, x_{5}\right\} ; F($ Cheap $)=\left\{x_{1}, x_{2}\right\}$ and $F(C$ lub house $)=\left\{x_{2}, x_{5}\right\}$. The soft set $(F, E)$ is a parameterized family $\left\{F\left(a_{i}\right), i=1,2,3,4,5\right\}$ of subsets of the set $U$ and gives us a collection of approximate descriptions of an object. Consider the function $F$ which is "apartments $(\cdot)$ " where $(\cdot)$ is to be filled up by a parameter $a \in E$. Thus, $F\left(a_{1}\right)$ means apartments (Expensive) whose functional value is the set $\left\{x_{3}, x_{4}\right\}$. This can be represented in the form of an information system as shown in Table 3 .

In this case, to define a soft set means to point out expensive apartments, apartments with swimming pool, apartments with club house, and so on. The soft set $(F, E)$ describes the overall charming of the apartment which a person is going to buy. Therefore, it is worth noting that the sets $F(a)$ may be empty for some $a \in A$. In classical mathematics, a mathematical model of an object is constructed and then we find the exact solution of this model. In general, mathematical model is too complicated and cannot find the exact solution. Therefore, in the next step, we introduce the notion of approximate solution and calculate that solution. Now, we state some of the fundamental concepts pertaining to soft set theory.

Table 3. Tabular representation of a soft set

\begin{tabular}{|l|l|l|l|l|l|}
\hline \multicolumn{1}{|c|}{$U$} & Expensive & Swimming pool & Children's park & Cheap & Club house \\
\hline$x_{1}$ & 0 & 1 & 0 & 1 & 0 \\
\hline$x_{2}$ & 0 & 0 & 1 & 1 & 1 \\
\hline$x_{3}$ & 1 & 1 & 0 & 0 & 0 \\
\hline$x_{4}$ & 1 & 0 & 1 & 0 & 0 \\
\hline$x_{5}$ & 0 & 0 & 1 & 0 & 1 \\
\hline$x_{6}$ & 0 & 1 & 0 & 0 & 0 \\
\hline
\end{tabular}




\subsection{Definition (Maji, Biswas, \& Roy, 2003)}

For two soft sets $\left(F, A_{1}\right)$ and $\left(G, A_{2}\right)$ over a common universe $U$, we say that $\left(F, A_{1}\right)$ is a soft subset of $\left(G, A_{2}\right)$ if the following conditions hold and we write $\left(F, A_{1}\right) \subseteq\left(G, A_{2}\right)$.

(i) $A_{1} \subseteq A_{2}$ and

(ii) $F(a)$ and $G(a)$ are identical approximations for all $a \in A$.

\subsection{Definition (Maji, Biswas, \& Roy, 2003)}

Two soft sets $\left(F, A_{1}\right)$ and $\left(G, A_{2}\right)$ over a common universe $U$ are said to be soft equal if the following conditions hold.

(i) $\left(F, A_{1}\right)$ is a soft subset of $\left(G, A_{2}\right)$, i.e., $\left(F, A_{1}\right) \subseteq\left(G, A_{2}\right)$ and

(ii) $\left(G, A_{2}\right)$ is a soft subset of $\left(F, A_{1}\right)$, i.e., $\left(G, A_{2}\right) \subseteq\left(F, A_{1}\right)$

Maji, Biswas \& Roy (2002) introduced the concept of fuzzy soft sets by combing the concept of fuzzy set into soft set. The author recalls the definitions and properties of fuzzy soft set.

\subsection{Definition (Maji, Biswas \& Roy, 2002)}

Let $\mathrm{U}$ be a universal set and $\mathrm{E}$ be the set of parameters. Let $\mathrm{P}(\mathrm{U})$ denote the set of all fuzzy sets of U. Let F': $\mathrm{A} \rightarrow \mathrm{P}(\mathrm{U})$ for $\mathrm{A} \subseteq \mathrm{E}$. Then a pair $\left(\mathrm{F}^{\prime}, \mathrm{A}\right)$ is called a fuzzy soft set

Let $\mathrm{U}$ be the set of four hospitals, given by, $U=\left\{h_{1}, h_{2}, h_{3}, h_{4}\right\}$. Let $E$ be the set of parameters, parameters are qualitative, given by $\mathrm{E}=\{$ excellent, outstanding, very good, good $\}$

$\mathrm{e}_{1}$ stands for parameter excellent; $\mathrm{e}_{2}$ stands for parameter outstanding; $\mathrm{e}_{3}$ stands for parameter very good; $\mathrm{e}_{4}$ stands for parameter good.

Now suppose that,

$\mathrm{F}^{\prime}\left(\mathrm{e}_{1}\right)=\left\{\mathrm{h}_{1} / .3, \mathrm{~h}_{2} / .8, \mathrm{~h}_{3} / .4, \mathrm{~h}_{4} / .5\right\}$.

$F^{\prime}\left(\mathrm{e}_{2}\right)=\left\{\mathrm{h}_{1} / .9, \mathrm{~h}_{2} / .6, \mathrm{~h}_{3} / .7\right\}$.

$\mathrm{F}^{\prime}\left(\mathrm{e}_{3}\right)=\left\{\mathrm{h}_{1} / .7, \mathrm{~h}_{2} / .8, \mathrm{~h}_{3} / 1, \mathrm{~h}_{4} / .5\right\}$.

$\mathrm{F}^{\prime}\left(\mathrm{e}_{4}\right)=\left\{\mathrm{h}_{1} / .1, \mathrm{~h}_{2} / .3, \mathrm{~h}_{3} / .4, \mathrm{~h}_{4} / .2\right\}$

Then fuzzy soft set is given by

$\left(\mathrm{F}^{\prime}, \mathrm{A}\right)=\left\{\right.$ Excellent patient service $=\left\{\mathrm{h}_{1} / .3, \mathrm{~h}_{2} / .8, \mathrm{~h}_{3} / .4, \mathrm{~h}_{4} / .5\right\}$,

Outstanding patient service $=\left\{\mathrm{h}_{1} / .9, \mathrm{~h}_{2} / .6, \mathrm{~h}_{3} / .7\right\}$,

Very good patient service $=\left\{\mathrm{h}_{1} / .7, \mathrm{~h}_{2} / .8, \mathrm{~h}_{3} / 1, \mathrm{~h}_{4} / .5\right\}$,

Good patient service $\left.=\left\{\mathrm{h}_{1} / .1, \mathrm{~h}_{2} / .3, \mathrm{~h}_{3} / .4, \mathrm{~h}_{4} / .2\right\}\right\}$

The fuzzy soft set is represented in tabular form (Table 4)

Few properties of fuzzy subset is defined below

\subsection{Definition}

For two fuzzy soft sets $\left(F^{\prime}, A_{1}\right)$ and $\left(G^{\prime}, A_{2}\right)$ over a common universe $U,\left(F^{\prime}, A_{1}\right)$ is a fuzzy soft subset of $\left(G^{\prime}, A_{2}\right)$ if 
Table 4. Tabular representation of fuzzy soft set

\begin{tabular}{|l|l|l|l|l|}
\hline & \multicolumn{1}{|c|}{$\mathbf{e}_{1}$} & \multicolumn{1}{c|}{$\mathbf{e}_{2}$} & \multicolumn{1}{c|}{$\mathbf{e}_{3}$} & \multicolumn{1}{c|}{$\mathbf{e}_{4}$} \\
\hline$h_{1}$ & 0.3 & 0.9 & 0.7 & 0.1 \\
\hline$h_{2}$ & 0.8 & 0.6 & 0.8 & 0.3 \\
\hline$h_{3}$ & 0.4 & 0.7 & 1 & 0.4 \\
\hline$h_{4}$ & 0.5 & 0 & 0.5 & 0.2 \\
\hline
\end{tabular}

1. $\mathrm{A}_{1} \subseteq \mathrm{A}_{2}$

2. $\mathrm{F}^{\prime}(\mathrm{a}) \leq \mathrm{G}^{\prime}(\mathrm{a}) \forall \mathrm{a} \subseteq \mathrm{A}_{1}$

\subsection{Definition}

1. Soft set is a special case of fuzzy soft set

2. A fuzzy soft set (F', A) is said to be universal fuzzy soft set if $F^{\prime}(a)=1 \forall a \in A$

3. A fuzzy soft set (F', A) is said to be normal fuzzy soft set if $\mathrm{F}^{\prime}(\mathrm{a})=0 \quad \forall \mathrm{a} \in \mathrm{A}$

4. Complement of a fuzzy soft set (F', A) is given by (F', A $)^{c}=\left(1-F^{\prime}(a), A\right) \forall a \in A$

\section{PROPOSED FRAMEWORK}

In this section, we propose a decision-making model for an information system. The proposed model consists of two stages: Stage I (pre-process) and Stage II (post-process). An abstract view of the model is represented in Figure 1. In general, the data in an information system are in multiple formats containing both qualitative and/or quantitative data. Hence, the quantitative data have to be converted into qualitative data. In the pre-process stage, the data is cleaned and aggregated; further, the quantitative data is processed by using a RSFAS (rough set in a fuzzy approximation space) technique. In addition to this, the model has the provision of rough set reduction techniques to reduce the number of attributes that do not have an influence in the information system. Further, based on the classification obtained during the pre-process phase, FSS (fuzzy soft set) techniques are used in the post-process phase to discover decisions from the information system. The main advantage of this model is that, it works for both qualitative and quantitative data. In addition, it gives due and exact importance to data values instead of categorizing them into two classes ( 0 and 1$)$.

\subsection{Stage I (Pre-Process) Design}

This section presents the design of the pre-process phase which consists of understanding the problem along with the target data, data cleaning, fuzzy proximity relation, and data classification as shown in Figure 2. Defining the problem and incorporating prior knowledge are the fundamental steps of any model. In addition, a target dataset-on which decision mining is to be performed - is found. For each parameter, near-equivalence classes are computed using a fuzzy proximity relation as discussed in Section 3.1. In order to identify the almost indiscernibility among the objects, a fuzzy proximity relation as discussed in section 3.1. In order to identify the almost indiscernibility among the objects, a fuzzy proximity relation $R\left(x_{i}, x_{j}\right)$ is defined among the objects $x_{i}$ and $x_{j}$, where

$$
R\left(x_{i}, x_{j}\right)=1-\frac{\left|V_{x_{i}}-V_{x_{j}}\right|}{\text { Mean value }}
$$


Figure 1. An abstract view of proposed model

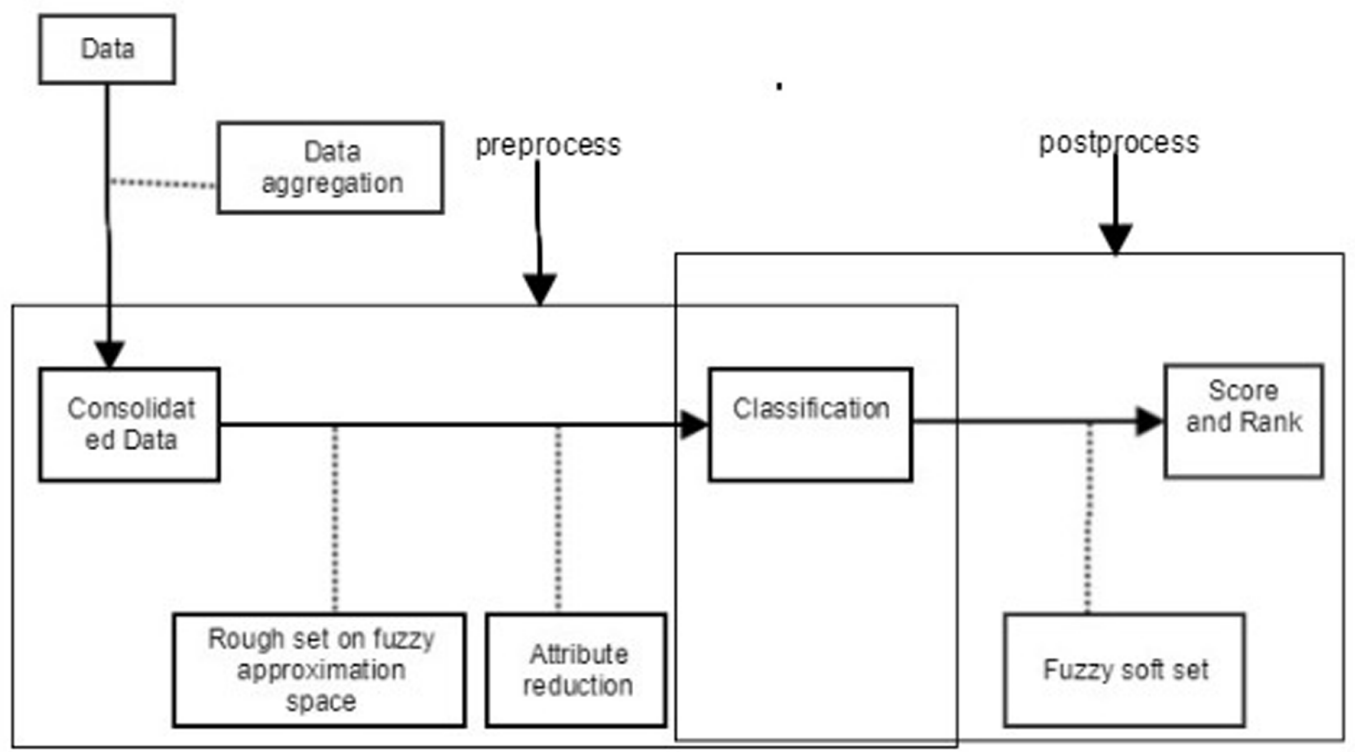

$V_{x_{i}}$ and $V_{x_{j}}$ are the values of objects $x_{i}$ and $x_{j}$; mean value is the average value of the parameter for all the objects in the information system. The membership function has been adjusted in such a manner that their values lie in $[0,1]$ and the function must also be symmetric. The fuzzy proximity relation identifies the near indiscernibility among the objects and induces $\alpha$-equivalence classes. A target dataset is prepared which would be processed by rough set with fuzzy approximation space. For each attribute $\alpha$-equivalence class based on indiscernibility relation is computed. The fuzzy proximity relation $\mathrm{R}$ is framed, subsequently for each attribute check whether $\mu_{R}(x, y) \geq \alpha ; 0 \leq \alpha \leq 1$ . If it is so, further we check for third attribute $\mathrm{z}$,

Whether $\mu_{R}(x, y) \geq \alpha$ and $\mu_{R}(y, z) \geq \alpha$, if it so class consist of attributes $\{\mathrm{x}, \mathrm{y}, \mathrm{z}\}$. Similarly, association between all the attributes are determined.

\subsection{Stage II (Post-Process) Design}

In this section the authors discuss how fuzzy soft set techniques can be used to obtain decisions. The classification obtained in the pre-process is the input to the post-process. Let $U=\left\{x_{1}, x_{2}, x_{3}, \ldots, x_{n}\right\}$ be the universe of discourse. Let the classification obtained by the $i^{t h}$ parameter $\left(a_{i}\right)$ be $U / R_{\alpha}^{a_{i}}$. Let us assume the classification $U / R_{\alpha}^{a_{i}}$ contains $q$-number of equivalence classes, $C_{j} ; 1 \leq j \leq q$. Therefore,

$$
U / R_{\alpha}^{a_{i}}=\left\{C_{1}, C_{2}, C_{3}, \ldots, C_{q}\right\}
$$

For tabular representation of a fuzzy soft set, computation of the entries of the table which is done as follows:

Let the classification $C_{J}$ contains N- objects; $\left|C_{J}\right|=N$. In order to obtain the tabular entries for the $i^{\text {th }}$ parameter $a_{i}$, compute $\mu^{a_{i}}$ for each equivalence class $C_{J} \in U / R_{\alpha}^{a_{i}}$, where 
Figure 2. Detailed pre-process architecture

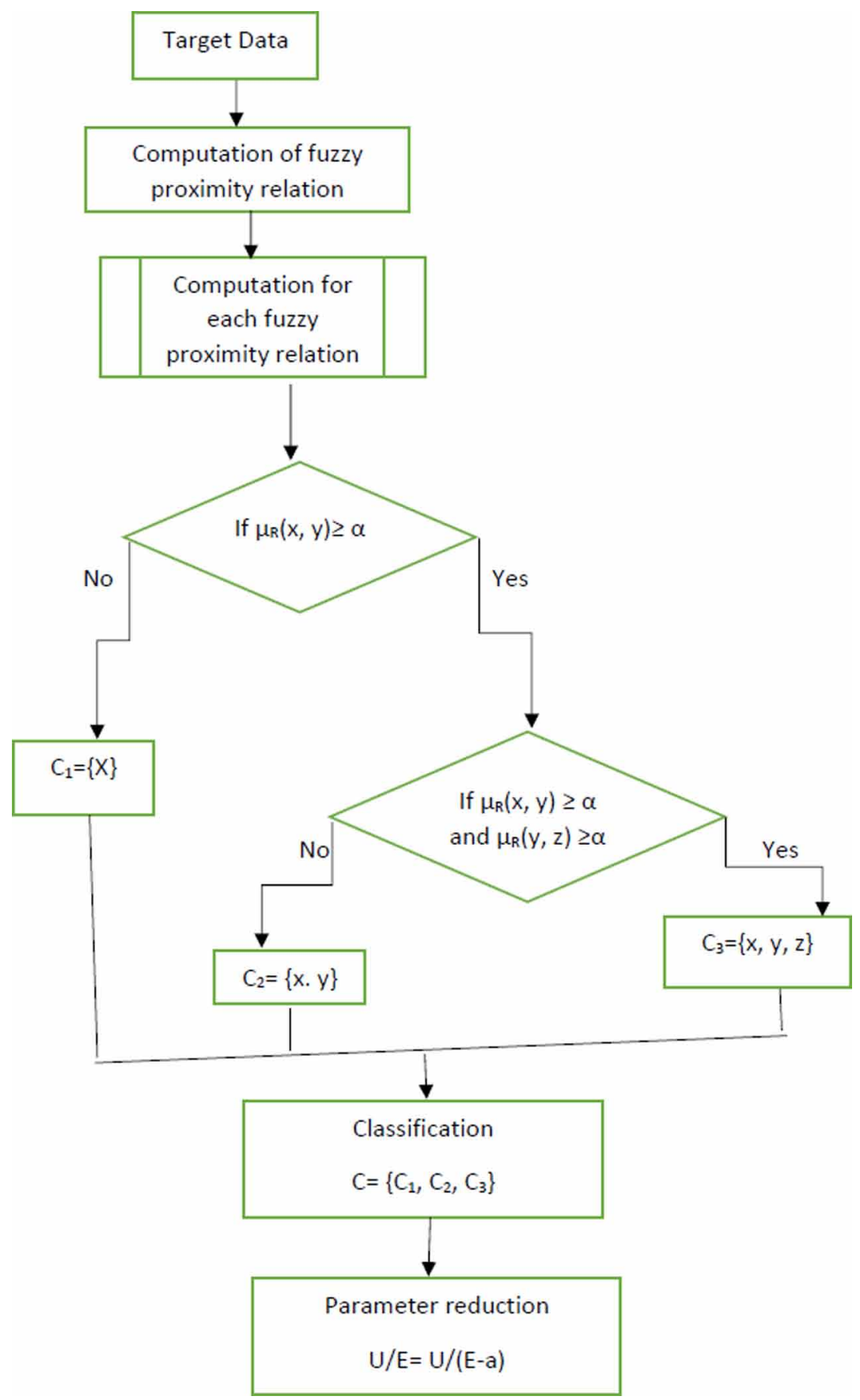




$$
\mu^{a_{i}}=\frac{\sum V_{x_{t}}}{m \times \text { Maximum value of parameter } a_{i}} ; x_{t} \in C_{J}
$$

Compute $\mu^{a_{i}}$ for each $a_{i} \in E$. From the tabular representation of fuzzy soft set, one can obtain the decisions based on the choice value. The choice value of an object $x_{k} \in U$ is $C_{v_{k}}$ and is given as $C_{v_{k}}=\sum_{a_{i} \in E} \mu_{k}^{a_{i}}$

where $\mu_{k}^{a_{i}}$ are the entries in the table of the soft set. Now, an algorithm is proposed for decision making
Algorithm
Input: Classification obtained in the pre-process
Output: Object having highest value.

1. For tabular representation of fuzzy soft set, compute entries of the table by using

$$
\mu^{a_{i}}=\frac{\sum V_{x_{t}}}{N \times \text { Maximum value of parameter } a_{i}} ; x_{t} \in C_{J}
$$

2. Determine choice value of each object of fuzzy soft set by using

$$
C_{v_{k}}=\sum_{a_{i} \in E} \mu_{k}^{a_{i}}
$$

3. Find the object for which the choice value is maximum

4. If more than one object has the same choice value, then

a) Compute for those objects $\delta^{m n}=\left|\mu^{a_{m}}-\mu^{a_{n}}\right|$ and $\Delta=\sum_{m} \sum_{n(m \neq n)} \delta^{m n}$

Find the object having minimum $\Delta$ value.

\section{EMPIRICAL STUDY ON RANKING HOSPITALS}

This section presents a real-life application to demonstrate the model. In order to validate the proposed model, the authors consider an information system which is a collection of USA hospitals by region. The objective is to compare the regions for hospital service on topics that are important to patients and consumers. As healthcare needs transparency, it is preferred to have a public reporting data.

\subsection{Stage I (Empirical Study)}

The HCAHPS (Hospital consumer assessment of healthcare providers and systems) survey is annual survey and the result is publicly reported. The survey is about the patient's experience who are recently discharged and it is conducted in random for adult inpatients between 2 days and six weeks after discharge. The survey is about the various factors of hospital care according to patient's perceptiveness. The measures are communication with nurses $(\mathrm{CN})$, communication with doctors $(\mathrm{CD})$, responsiveness of hospital staff (RHS), pain management (PM), communication about medicines (CM), cleanliness of hospital environment (CHE), quietness of hospital environment (QHE), discharge information (DI), care transition (CT), hospital rating (HR) and recommend the hospital (RH). 
Groups of states defined by the United States census bureau are listed below

New England (NE) - CT, ME, MA, NH, RI, VT

Mid-Atlantic (MA) - NJ, NY, PA

South Atlantic (SA) - DC, DE, FL, GA, MD, NC, SC, VA, WV

East North Central (ENC) - IL, IN, MI, OH, WI

East South Central (ESC) - AL, KY, MS, TN

West North Central (WNC) - IA, KS, MN, MO, NE, ND, SD

West South Central (WSC) - AR, LA, OK, TX

Mountain (M) - AZ, CO, ID, MT, NM, NV, UT, WY

Pacific (P) - AK, CA, HI, OR, WA

Dataset used for investigation is presented in Table 5. The fuzzy proximity relation corresponding to parameters CN, CD, RHS, PM, CM, CHE, QHE, DI, CT, HR and RH are computed and presented in Tables 6-16 respectively.

We have considered almost similarity of $98 \%$ i.e. $\alpha \geq 0.98$; it is evident from Table 6 that

Table 5. Information system under study

\begin{tabular}{|l|l|l|l|l|l|l|l|l|l|l|l|}
\hline & \multicolumn{1}{|c|}{ CN } & \multicolumn{1}{|c|}{ CD } & RHS & \multicolumn{1}{|c|}{ PM } & \multicolumn{1}{|c|}{ CM } & CHE & QHE & \multicolumn{1}{c|}{ DI } & CT & HR & RH \\
\hline NE & 81.3 & 81.7 & 69 & 71.5 & 65.8 & 75.8 & 55 & 89 & 54.3 & 72 & 73.8 \\
\hline MA & 78.3 & 78.3 & 64 & 69 & 61.7 & 71 & 54.3 & 86 & 49.3 & 67 & 67.3 \\
\hline SA & 78.7 & 80.4 & 64.6 & 69.7 & 63.2 & 70.4 & 60.9 & 86.2 & 49.8 & 68.6 & 68.6 \\
\hline ENC & 81.8 & 82 & 71.2 & 72.2 & 66 & 76.2 & 62.2 & 88.4 & 54.2 & 74.4 & 72.8 \\
\hline ESC & 81.5 & 85.5 & 69.8 & 72.5 & 66.5 & 74 & 70 & 86 & 51 & 72.3 & 70.8 \\
\hline WNC & 82.3 & 84.4 & 73.9 & 72.4 & 68 & 78.4 & 67.4 & 88 & 55.4 & 76.1 & 75.4 \\
\hline WSC & 81.8 & 84.5 & 71 & 73.5 & 67.5 & 75.5 & 70.3 & 86 & 53.8 & 74.3 & 73.3 \\
\hline M & 78.4 & 80.5 & 69.4 & 70.5 & 65 & 73.2 & 61.5 & 87.4 & 52.1 & 71.4 & 70.6 \\
\hline P & 78.2 & 80.4 & 68 & 69 & 64.2 & 74 & 57.2 & 87.2 & 51.4 & 70.2 & 71.8 \\
\hline
\end{tabular}

Table 6. Fuzzy proximity relation for attribute $\mathrm{CN}$

\begin{tabular}{|l|l|l|l|l|l|l|l|l|l|l|}
\hline \multicolumn{1}{|c|}{$\mathbf{R}^{\text {CN }}$} & \multicolumn{1}{|c|}{ NE } & \multicolumn{1}{|c|}{ MA } & \multicolumn{1}{|c|}{ SA } & \multicolumn{1}{|c|}{ ENC } & \multicolumn{1}{|c|}{ ESC } & \multicolumn{1}{|c|}{ WNC } & \multicolumn{1}{|c|}{ WSC } & M & P \\
\hline NE & 1 & 0.962 & 0.967 & 0.993 & 0.997 & 0.987 & 0.993 & 0.963 & 0.961 \\
\hline MA & 0.962 & 1 & 0.995 & 0.956 & 0.96 & 0.95 & 0.956 & 0.998 & 0.998 \\
\hline SA & 0.967 & 0.995 & 1 & 0.961 & 0.965 & 0.955 & 0.961 & 0.996 & 0.993 \\
\hline ENC & 0.993 & 0.956 & 0.961 & 1 & 0.996 & 0.993 & 1 & 0.957 & 0.955 \\
\hline ESC & 0.997 & 0.96 & 0.965 & 0.996 & 1 & 0.99 & 0.996 & 0.961 & 0.958 \\
\hline WNC & 0.987 & 0.95 & 0.955 & 0.993 & 0.99 & 1 & 0.993 & 0.963 & 0.961 \\
\hline WSC & 0.993 & 0.956 & 0.961 & 1 & 0.996 & 0.993 & 1 & 0.957 & 0.955 \\
\hline M & 0.963 & 0.998 & 0.996 & 0.957 & 0.961 & 0.963 & 0.957 & 1 & 0.997 \\
\hline P & 0.961 & 0.998 & 0.993 & 0.955 & 0.958 & 0.961 & 0.955 & 0.997 & 1 \\
\hline
\end{tabular}


$\mathrm{R}^{\mathrm{CN}}(\mathrm{NE}, \mathrm{NE})=1, \mathrm{R}^{\mathrm{CN}}(\mathrm{NE}, \mathrm{ENC})=0.993, \mathrm{R}^{\mathrm{CN}}(\mathrm{NE}, \mathrm{ESC})=0.997, \mathrm{R}^{\mathrm{CN}}(\mathrm{NE}, \mathrm{WNC})=0.987$, $\mathrm{R}^{\mathrm{CN}}(\mathrm{NE}, \mathrm{WSC})=0.993$;

$\mathrm{R}^{\mathrm{CN}}(\mathrm{MA}, \mathrm{SA})=0.995, \mathrm{R}^{\mathrm{CN}}(\mathrm{MA}, \mathrm{M})=0.998, \mathrm{R}^{\mathrm{CN}}(\mathrm{MA}, \mathrm{P})=0.998$

Hence fuzzy proximity relation for parameter $\mathrm{CN}$ is calculated as

$\mathrm{U} / \mathrm{R}_{\alpha}{ }^{\mathrm{CN}}=\{\{\mathrm{NE}, \mathrm{ENC}, \mathrm{ESC}, \mathrm{WNC}, \mathrm{WSC}\},\{\mathrm{MA}, \mathrm{SA}, \mathrm{M}, \mathrm{P}\}\}$

Similarly, $\alpha$ - equivalence class of parameters CD, RHS, PM, CM, CHE, QHE, DI, CT, HR, RH as computed from Table7-16 are given below

$\mathrm{U} / \mathrm{R}_{\alpha}{ }^{\mathrm{CD}}=\{\{\mathrm{NE}, \mathrm{SA}, \mathrm{ENC}, \mathrm{M}, \mathrm{P}\},\{\mathrm{ESC}, \mathrm{WNC}, \mathrm{WSC}\},\{\mathrm{MA}\}\}$

$\mathrm{U} / \mathrm{R}_{\alpha}{ }_{\alpha}{ }^{\mathrm{RHS}}=\{\{\mathrm{NE}, \mathrm{ESC}, \mathrm{ENC}, \mathrm{WSC}, \mathrm{M}, \mathrm{P}\},\{\mathrm{MA}, \mathrm{SA}\} .\{\mathrm{WNC}\}\}$

$\mathrm{U} / \mathrm{R}_{\alpha}^{\alpha}=\{\{\mathrm{NE}, \mathrm{ENC}, \mathrm{ESC}, \mathrm{WNC}, \mathrm{WSC}, \mathrm{MA}, \mathrm{SA}, \mathrm{M}, \mathrm{P}\}\}$

$\mathrm{U} / \mathrm{R}_{\alpha}^{\alpha}{ }^{\mathrm{CM}}=\{\{\mathrm{NE}, \mathrm{ENC}, \mathrm{ESC}, \mathrm{WNC}, \mathrm{WSC}, \mathrm{SA}, \mathrm{M}, \mathrm{P}\},\{\mathrm{MA}\}\}$

$\mathrm{U} / \mathrm{R}_{\alpha}^{\alpha} \mathrm{CHE}=\{\{\mathrm{NE}, \mathrm{ENC}, \mathrm{WSC}\},\{\mathrm{MA}, \mathrm{SA}\},\{\mathrm{ESC}, \mathrm{M}, \mathrm{P}\},\{\mathrm{WNC}\}\}$

$\mathrm{U} / \mathrm{R}_{\alpha}^{\alpha} \mathrm{QHE}=\{\{\mathrm{NE}, \mathrm{MA}\},\{\mathrm{ESC}, \mathrm{WSC}\},\{\mathrm{SA}, \mathrm{M}, \mathrm{ENC}\},\{\mathrm{WNC}\},\{\mathrm{P}\}\}$

$\mathrm{U} / \mathrm{R}_{\alpha}{ }^{\mathrm{DI}}=\{\{\mathrm{NE}, \mathrm{ENC}, \mathrm{ESC}, \mathrm{WNC}, \mathrm{WSC}, \mathrm{MA}, \mathrm{SA}, \mathrm{M}, \mathrm{P}\}\}$

$\mathrm{U} / \mathrm{R}_{\alpha}{ }^{\mathrm{CT}}=\{\{\mathrm{NE}, \mathrm{ENC}, \mathrm{WSC}\},\{\mathrm{MA}, \mathrm{SA}\},\{\mathrm{ESC}, \mathrm{M}, \mathrm{P}\},\{\mathrm{WNC}\}\}$

$\mathrm{U} / \mathrm{R}_{\alpha}{ }^{\mathrm{HR}}=\{\{\mathrm{NE}, \mathrm{ESC}, \mathrm{M}, \mathrm{P}\},\{\mathrm{MA}\},\{\mathrm{SA}\},\{\mathrm{ENC}, \mathrm{WSC}\},\{\mathrm{WNC}\}\}$

$\mathrm{U} / \mathrm{R}_{\alpha}{ }^{\mathrm{RH}}=\{\{\mathrm{NE}, \mathrm{ENC}, \mathrm{WSC}, \mathrm{ESC}, \mathrm{M}, \mathrm{P}\},\{\mathrm{MA}, \mathrm{SA}\},\{\mathrm{WNC}\}\}$

Since $U / R_{\alpha}{ }^{P M}$ contains one class. It indicates $U / E=U /(E-P M)$.It shows all the parameter values of PM are $\alpha$-indiscernible. Hence the parameter PM may be excluded from the information system. Similarly the parameter DI also can be excluded.

\subsection{Stage II (Empirical Study)}

In this stage of postprocess analysis, let's consider the classification obtained for parameter CN. It is seen that the classification consists two classes.

Let $\mathrm{C}_{1}=\{\mathrm{NE}, \mathrm{ENC}, \mathrm{ESC}, \mathrm{WNC}, \mathrm{WSC}\}$ and $\left.\mathrm{C}_{2}=\{\mathrm{MA}, \mathrm{SA}, \mathrm{M}, \mathrm{P}\}\right\}$

The proposed algorithm for computing top rating was applied to the classifications obtained.

The value of $\mu^{\mathrm{CN}}$ for class $\mathrm{C}_{1}$ is computed as

$\mu^{\mathrm{CN}}=\frac{V_{x_{1}}+V_{x_{2}}+V_{x_{3}}+V_{x_{4}}+V_{x_{5}}}{5 \times C N \max }=\frac{81.3+81.8+81.5+82.3+81.8}{5 \times 82.3}=0.993$

Similarly, the value of $\mu^{\mathrm{CN}}$ for class $\mathrm{C}_{2}$ is computed as 0.952 . The computational procedure is repeated for each parameter CD, RHS, PM, CM, CHE, QHE, DI, CT, HR and RH. Now the output is fuzzy soft set values of the attributes which are represented in Table 17. However, the choice value $\left(\mathrm{C}_{\mathrm{v}}\right)$ of each object is presented in Table 18 .

In order to select the best region for hospital, proposed algorithm as discussed in section 5.2 is imposed. According to algorithm, the choice value of each region is computed and presented in Table 18.

\section{ANALYSIS OF THE EXPERIMENTAL RESULT}

It is evident from Table 18 that WNC has the highest choice value of 8.909; hence, it tops the list followed by WSC (with a choice value of 8.761) and ESC (with a choice value of 8.656). 
Table 7. Fuzzy proximity relation for attribute CD

\begin{tabular}{|l|l|l|l|l|l|l|l|l|l|l|}
\hline \multicolumn{1}{|c|}{$\mathbf{R}^{\text {CD }}$} & \multicolumn{1}{|c|}{ NE } & \multicolumn{1}{|c|}{ MA } & \multicolumn{1}{|c|}{ SA } & \multicolumn{1}{|c|}{ ENC } & \multicolumn{1}{|c|}{ ESC } & \multicolumn{1}{|c|}{ WNC } & \multicolumn{1}{|c|}{ WSC } & M & P \\
\hline NE & 1 & 0.958 & 0.984 & 0.996 & 0.953 & 0.967 & 0.965 & 0.985 & 0.984 \\
\hline MA & 0.958 & 1 & 0.974 & 0.954 & 0.912 & 0.925 & 0.924 & 0.973 & 0.974 \\
\hline SA & 0.984 & 0.974 & 1 & 0.98 & 0.937 & 0.951 & 0.95 & 0.998 & 1 \\
\hline ENC & 0.996 & 0.954 & 0.98 & 1 & 0.957 & 0.97 & 0.969 & 0.981 & 0.98 \\
\hline ESC & 0.953 & 0.912 & 0.937 & 0.957 & 1 & 0.986 & 0.987 & 0.939 & 0.937 \\
\hline WNC & 0.967 & 0.925 & 0.951 & 0.97 & 0.986 & 1 & 0.998 & 0.952 & 0.951 \\
\hline WSC & 0.965 & 0.924 & 0.95 & 0.969 & 0.987 & 0.998 & 1 & 0.951 & 0.95 \\
\hline M & 0.985 & 0.973 & 0.998 & 0.981 & 0.939 & 0.952 & 0.951 & 1 & 0.998 \\
\hline P & 0.984 & 0.974 & 1 & 0.98 & 0.937 & 0.951 & 0.95 & 0.998 & 1 \\
\hline
\end{tabular}

Table 8. Fuzzy proximity relation for attribute RHS

\begin{tabular}{|l|l|l|l|l|l|l|l|l|l|l|}
\hline \multicolumn{1}{|c|}{$\mathbf{R}^{\text {RHS }}$} & \multicolumn{1}{|c|}{ NE } & \multicolumn{1}{|c|}{ MA } & \multicolumn{1}{|c|}{ SA } & \multicolumn{1}{|c|}{ ENC } & \multicolumn{1}{|c|}{ ESC } & \multicolumn{1}{|c|}{ WNC } & \multicolumn{1}{|c|}{ WSC } & M & P \\
\hline NE & 1 & 0.927 & 0.936 & 0.968 & 0.988 & 0.928 & 0.971 & 0.994 & 0.985 \\
\hline MA & 0.927 & 1 & 0.991 & 0.895 & 0.915 & 0.856 & 0.898 & 0.921 & 0.942 \\
\hline SA & 0.936 & 0.991 & 1 & 0.904 & 0.924 & 0.865 & 0.907 & 0.93 & 0.95 \\
\hline ENC & 0.968 & 0.895 & 0.904 & 1 & 0.979 & 0.96 & 0.997 & 0.973 & 0.953 \\
\hline ESC & 0.988 & 0.915 & 0.924 & 0.979 & 1 & 0.94 & 0.982 & 0.994 & 0.973 \\
\hline WNC & 0.928 & 0.856 & 0.865 & 0.96 & 0.94 & 1 & 0.957 & 0.934 & 0.914 \\
\hline WSC & 0.971 & 0.898 & 0.907 & 0.997 & 0.982 & 0.957 & 1 & 0.976 & 0.956 \\
\hline M & 0.994 & 0.921 & 0.93 & 0.973 & 0.994 & 0.934 & 0.976 & 1 & 0.979 \\
\hline P & 0.985 & 0.942 & 0.95 & 0.953 & 0.973 & 0.914 & 0.956 & 0.979 & 1 \\
\hline
\end{tabular}

Table 9. Fuzzy proximity relation for attribute PM

\begin{tabular}{|l|l|l|l|l|l|l|l|l|l|l|}
\hline \multicolumn{1}{|c|}{$\mathbf{R}^{\mathbf{P M}}$} & \multicolumn{1}{|c|}{ NE } & \multicolumn{1}{|c|}{ MA } & \multicolumn{1}{|c|}{ SA } & \multicolumn{1}{|c|}{ ENC } & \multicolumn{1}{|c|}{ ESC } & \multicolumn{1}{|c|}{ WNC } & \multicolumn{1}{|c|}{ WSC } & \multicolumn{1}{|c|}{ P } & \multicolumn{1}{|c|}{ P } \\
\hline NE & 1 & 0.964 & 0.974 & 0.99 & 0.985 & 0.987 & 0.971 & 0.985 & 0.964 \\
\hline MA & 0.964 & 1 & 0.99 & 0.954 & 0.95 & 0.952 & 0.936 & 0.978 & 1 \\
\hline SA & 0.974 & 0.99 & 1 & 0.964 & 0.96 & 0.961 & 0.946 & 0.988 & 0.99 \\
\hline ENC & 0.99 & 0.954 & 0.964 & 1 & 0.995 & 0.997 & 0.981 & 0.976 & 0.954 \\
\hline ESC & 0.985 & 0.95 & 0.96 & 0.995 & 1 & 0.998 & 0.985 & 0.971 & 0.95 \\
\hline WNC & 0.987 & 0.952 & 0.961 & 0.997 & 0.998 & 1 & 0.984 & 0.973 & 0.952 \\
\hline WSC & 0.971 & 0.936 & 0.946 & 0.981 & 0.985 & 0.984 & 1 & 0.957 & 0.936 \\
\hline M & 0.985 & 0.978 & 0.988 & 0.976 & 0.971 & 0.973 & 0.957 & 1 & 0.978 \\
\hline P & 0.964 & 1 & 0.99 & 0.954 & 0.95 & 0.952 & 0.936 & 0.978 & 1 \\
\hline
\end{tabular}


Table 10. Fuzzy proximity relation for attribute CM

\begin{tabular}{|l|l|l|l|l|l|l|l|l|l|}
\hline \multicolumn{1}{|c|}{$\mathbf{R}^{\text {CM }}$} & \multicolumn{1}{|c|}{ NE } & \multicolumn{1}{|c|}{ MA } & \multicolumn{1}{|c|}{ SA } & \multicolumn{1}{|c|}{ ENC } & \multicolumn{1}{|c|}{ ESC } & \multicolumn{1}{|c|}{ WNC } & \multicolumn{1}{|c|}{ WSC } & M & P \\
\hline NE & 1 & 0.936 & 0.96 & 0.996 & 0.989 & 0.966 & 0.973 & 0.987 & 0.975 \\
\hline MA & 0.936 & 1 & 0.976 & 0.933 & 0.926 & 0.903 & 0.91 & 0.949 & 0.961 \\
\hline SA & 0.96 & 0.976 & 1 & 0.956 & 0.949 & 0.926 & 0.933 & 0.972 & 0.984 \\
\hline ENC & 0.996 & 0.933 & 0.956 & 1 & 0.992 & 0.969 & 0.976 & 0.984 & 0.972 \\
\hline ESC & 0.989 & 0.926 & 0.949 & 0.992 & 1 & 0.976 & 0.984 & 0.976 & 0.964 \\
\hline WNC & 0.966 & 0.903 & 0.926 & 0.969 & 0.976 & 1 & 0.992 & 0.953 & 0.941 \\
\hline WSC & 0.973 & 0.91 & 0.933 & 0.976 & 0.984 & 0.992 & 1 & 0.961 & 0.949 \\
\hline M & 0.987 & 0.949 & 0.972 & 0.984 & 0.976 & 0.953 & 0.961 & 1 & 0.987 \\
\hline P & 0.975 & 0.961 & 0.984 & 0.972 & 0.964 & 0.941 & 0.949 & 0.987 & 1 \\
\hline
\end{tabular}

Table 11. Fuzzy proximity relation for attribute CHE

\begin{tabular}{|l|l|l|l|l|l|l|l|l|l|l|}
\hline \multicolumn{1}{|c|}{$\mathbf{R}^{\text {CHE }}$} & \multicolumn{1}{|c|}{ NE } & \multicolumn{1}{|c|}{ MA } & \multicolumn{1}{|c|}{ SA } & \multicolumn{1}{|c|}{ ENC } & \multicolumn{1}{|c|}{ ESC } & \multicolumn{1}{|c|}{ WNC } & \multicolumn{1}{|c|}{ WSC } & M & \multicolumn{1}{|c|}{ P } \\
\hline NE & 1 & 0.935 & 0.927 & 0.994 & 0.975 & 0.964 & 0.995 & 0.964 & 0.975 \\
\hline MA & 0.935 & 1 & 0.991 & 0.929 & 0.959 & 0.9 & 0.939 & 0.97 & 0.959 \\
\hline SA & 0.927 & 0.991 & 1 & 0.921 & 0.951 & 0.891 & 0.931 & 0.962 & 0.951 \\
\hline ENC & 0.994 & 0.929 & 0.921 & 1 & 0.97 & 0.97 & 0.99 & 0.959 & 0.97 \\
\hline ESC & 0.975 & 0.959 & 0.951 & 0.97 & 1 & 0.94 & 0.979 & 0.989 & 1 \\
\hline WNC & 0.964 & 0.9 & 0.891 & 0.97 & 0.94 & 1 & 0.96 & 0.929 & 0.94 \\
\hline WSC & 0.995 & 0.939 & 0.931 & 0.99 & 0.979 & 0.96 & 1 & 0.968 & 0.979 \\
\hline M & 0.964 & 0.97 & 0.962 & 0.959 & 0.989 & 0.929 & 0.968 & 1 & 0.989 \\
\hline P & 0.975 & 0.959 & 0.951 & 0.97 & 1 & 0.94 & 0.979 & 0.989 & 1 \\
\hline
\end{tabular}

\section{Table 12. Fuzzy proximity relation for attribute QHE}

\begin{tabular}{|l|l|l|l|l|l|l|l|l|l|l|}
\hline \multicolumn{1}{|c|}{$\mathbf{R}^{\text {QHE }}$} & \multicolumn{1}{|c|}{ NE } & \multicolumn{1}{|c|}{ MA } & \multicolumn{1}{|c|}{ SA } & \multicolumn{1}{|c|}{ ENC } & \multicolumn{1}{|c|}{ ESC } & \multicolumn{1}{|c|}{ WNC } & \multicolumn{1}{|c|}{ WSC } & M & P \\
\hline NE & 1 & 0.988 & 0.906 & 0.885 & 0.761 & 0.803 & 0.757 & 0.896 & 0.965 \\
\hline MA & 0.988 & 1 & 0.895 & 0.874 & 0.75 & 0.792 & 0.746 & 0.885 & 0.953 \\
\hline SA & 0.906 & 0.895 & 1 & 0.979 & 0.823 & 0.896 & 0.85 & 0.99 & 0.941 \\
\hline ENC & 0.885 & 0.874 & 0.979 & 1 & 0.876 & 0.917 & 0.871 & 0.988 & 0.92 \\
\hline ESC & 0.761 & 0.75 & 0.823 & 0.876 & 1 & 0.958 & 0.995 & 0.865 & 0.796 \\
\hline WNC & 0.803 & 0.792 & 0.896 & 0.917 & 0.958 & 1 & 0.953 & 0.906 & 0.885 \\
\hline WSC & 0.757 & 0.746 & 0.85 & 0.871 & 0.995 & 0.953 & 1 & 0.86 & 0.792 \\
\hline M & 0.896 & 0.885 & 0.99 & 0.988 & 0.865 & 0.906 & 0.86 & 1 & 0.931 \\
\hline P & 0.965 & 0.953 & 0.941 & 0.92 & 0.796 & 0.885 & 0.792 & 0.931 & 1 \\
\hline
\end{tabular}


Table 13. Fuzzy proximity relation for attribute DI

\begin{tabular}{|l|l|l|l|l|l|l|l|l|l|l|}
\hline \multicolumn{1}{|c|}{$\mathbf{R}^{\text {DI }}$} & \multicolumn{1}{|c|}{ NE } & \multicolumn{1}{|c|}{ MA } & \multicolumn{1}{|c|}{ SA } & \multicolumn{1}{|c|}{ ENC } & \multicolumn{1}{|c|}{ ESC } & \multicolumn{1}{|c|}{ WNC } & \multicolumn{1}{|c|}{ WSC } & M & P \\
\hline NE & 1 & 0.965 & 0.967 & 0.993 & 0.965 & 0.988 & 0.965 & 0.981 & 0.979 \\
\hline MA & 0.965 & 1 & 0.997 & 0.972 & 1 & 0.977 & 1 & 0.983 & 0.986 \\
\hline SA & 0.967 & 0.997 & 1 & 0.974 & 0.997 & 0.979 & 0.997 & 0.986 & 0.988 \\
\hline ENC & 0.993 & 0.972 & 0.974 & 1 & 0.972 & 0.995 & 0.972 & 0.988 & 0.986 \\
\hline ESC & 0.965 & 1 & 0.997 & 0.972 & 1 & 0.977 & 1 & 0.983 & 0.986 \\
\hline WNC & 0.988 & 0.977 & 0.979 & 0.995 & 0.977 & 1 & 0.977 & 0.993 & 0.99 \\
\hline WSC & 0.965 & 1 & 0.997 & 0.972 & 1 & 0.977 & 1 & 0.983 & 0.986 \\
\hline M & 0.981 & 0.983 & 0.986 & 0.988 & 0.983 & 0.993 & 0.983 & 1 & 0.997 \\
\hline P & 0.979 & 0.986 & 0.988 & 0.986 & 0.986 & 0.99 & 0.986 & 0.997 & 1 \\
\hline
\end{tabular}

Table 14. Fuzzy proximity relation for attribute CT

\begin{tabular}{|l|l|l|l|l|l|l|l|l|l|}
\hline \multicolumn{1}{|c|}{$\mathbf{R}^{\text {CT }}$} & \multicolumn{1}{|c|}{ NE } & \multicolumn{1}{|c|}{ MA } & \multicolumn{1}{|c|}{ SA } & \multicolumn{1}{|c|}{ ENC } & \multicolumn{1}{|c|}{ ESC } & \multicolumn{1}{|c|}{ WNC } & \multicolumn{1}{|c|}{ WSC } & M & P \\
\hline NE & 1 & 0.903 & 0.913 & 0.998 & 0.936 & 0.978 & 0.99 & 0.957 & 0.944 \\
\hline MA & 0.903 & 1 & 0.99 & 0.905 & 0.967 & 0.882 & 0.913 & 0.946 & 0.959 \\
\hline SA & 0.913 & 0.99 & 1 & 0.915 & 0.976 & 0.892 & 0.923 & 0.955 & 0.969 \\
\hline ENC & 0.998 & 0.905 & 0.915 & 1 & 0.938 & 0.976 & 0.992 & 0.959 & 0.946 \\
\hline ESC & 0.936 & 0.967 & 0.976 & 0.938 & 1 & 0.915 & 0.946 & 0.978 & 0.992 \\
\hline WNC & 0.978 & 0.882 & 0.892 & 0.976 & 0.915 & 1 & 0.969 & 0.936 & 0.923 \\
\hline WSC & 0.99 & 0.913 & 0.923 & 0.992 & 0.946 & 0.969 & 1 & 0.967 & 0.953 \\
\hline M & 0.957 & 0.946 & 0.955 & 0.959 & 0.978 & 0.936 & 0.967 & 1 & 0.986 \\
\hline P & 0.944 & 0.959 & 0.969 & 0.946 & 0.992 & 0.923 & 0.953 & 0.986 & 1 \\
\hline
\end{tabular}

Table 15. Fuzzy proximity relation for attribute HR

\begin{tabular}{|l|l|l|l|l|l|l|l|l|l|}
\hline \multicolumn{1}{|c|}{$\mathbf{R}^{\text {HR }}$} & \multicolumn{1}{|c|}{ NE } & \multicolumn{1}{|c|}{ MA } & \multicolumn{1}{|c|}{ SA } & \multicolumn{1}{|c|}{ ENC } & \multicolumn{1}{|c|}{ ESC } & \multicolumn{1}{|c|}{ WNC } & \multicolumn{1}{|c|}{ WSC } & M & P \\
\hline NE & 1 & 0.93 & 0.952 & 0.966 & 0.995 & 0.943 & 0.968 & 0.991 & 0.975 \\
\hline MA & 0.93 & 1 & 0.977 & 0.897 & 0.926 & 0.873 & 0.898 & 0.938 & 0.955 \\
\hline SA & 0.952 & 0.977 & 1 & 0.919 & 0.948 & 0.895 & 0.92 & 0.961 & 0.977 \\
\hline ENC & 0.966 & 0.897 & 0.919 & 1 & 0.97 & 0.976 & 0.998 & 0.958 & 0.941 \\
\hline ESC & 0.995 & 0.926 & 0.948 & 0.97 & 1 & 0.947 & 0.972 & 0.987 & 0.97 \\
\hline WNC & 0.943 & 0.873 & 0.895 & 0.976 & 0.947 & 1 & 0.975 & 0.934 & 0.918 \\
\hline WSC & 0.968 & 0.898 & 0.92 & 0.998 & 0.972 & 0.975 & 1 & 0.959 & 0.943 \\
\hline M & 0.991 & 0.938 & 0.961 & 0.958 & 0.987 & 0.934 & 0.959 & 1 & 0.983 \\
\hline P & 0.975 & 0.955 & 0.977 & 0.941 & 0.97 & 0.918 & 0.943 & 0.983 & 1 \\
\hline
\end{tabular}


Table 16. Fuzzy proximity relation for attribute RH

\begin{tabular}{|l|l|l|l|l|l|l|l|l|l|}
\hline \multicolumn{1}{|c|}{$\mathbf{R}^{\text {RH }}$} & \multicolumn{1}{|c|}{ NE } & \multicolumn{1}{|c|}{ MA } & \multicolumn{1}{|c|}{ SA } & \multicolumn{1}{|c|}{ ENC } & \multicolumn{1}{|c|}{ ESC } & \multicolumn{1}{|c|}{ WNC } & \multicolumn{1}{|c|}{ WSC } & M & P \\
\hline NE & 1 & 0.909 & 0.927 & 0.986 & 0.958 & 0.977 & 0.993 & 0.955 & 0.972 \\
\hline MA & 0.909 & 1 & 0.981 & 0.923 & 0.951 & 0.987 & 0.916 & 0.954 & 0.937 \\
\hline SA & 0.927 & 0.981 & 1 & 0.941 & 0.969 & 0.905 & 0.934 & 0.972 & 0.955 \\
\hline ENC & 0.986 & 0.923 & 0.941 & 1 & 0.972 & 0.963 & 0.993 & 0.969 & 0.986 \\
\hline ESC & 0.958 & 0.951 & 0.969 & 0.972 & 1 & 0.936 & 0.965 & 0.997 & 0.986 \\
\hline WNC & 0.977 & 0.887 & 0.905 & 0.963 & 0.936 & 1 & 0.97 & 0.933 & 0.95 \\
\hline WSC & 0.993 & 0.916 & 0.934 & 0.993 & 0.965 & 0.97 & 1 & 0.962 & 0.979 \\
\hline M & 0.955 & 0.954 & 0.972 & 0.969 & 0.997 & 0.933 & 0.962 & 1 & 0.983 \\
\hline P & 0.972 & 0.937 & 0.955 & 0.986 & 0.986 & 0.95 & 0.979 & 0.983 & 1 \\
\hline
\end{tabular}

In order to have more simulation of the proposed model, data results from the HCAHPS survey of discharged patients (between January 2017 to December 2017) are used for testing the model. The data are processed in Stage I and Stage II exactly in the same way as the previous data have been. Keeping the length of the paper in view, we have omitted the detailed step-by-step procedure. However, the final result is represented in Table 19.

In order to give them more visibility, the scores are visualized in Figure 3 below. It is clear that the highest histogram bar is that of WNC, which stands at the top position

Further, the authors analyze FSS (fuzzy soft set) values in Table 17 from a different perspective. They now define a universal fuzzy soft set information system-as is represented in Table 20.

Now the Hamming distance between the corresponding entries of Table 17 and Table 20 is computed. The hamming distance between $\mu_{\mathrm{A}}(\mathrm{x})$ and $\mu_{\mathrm{B}}(\mathrm{x})$ is given by $\frac{1}{2} \sum\left|\mu_{A}(x)-\mu_{B}(x)\right|$. The distances, calculated according to region, are presented in Table 21.

From Table 21, it is clear that WNC is least distant from the target set. Hence, the service offered by WNC is most optimized as compared to its counterparts.The comparative choice value score, as listed by region (for 2016 and 2017 discharge data), is represented graphically in Figure 4.

\subsection{Comparative Analysis with Existing Techniques}

It is evident from the literature that most of the agency rankings are based on statistical techniques. They measure various quality parameters and aggregate them to calculate the final score. Hence, the proposed research is presented in comparison to the statistical model to show the viability of its result. The empirical data from the results of the HCAHPS survey for discharged patients in 2016 are taken into consideration in the analysis of the results.

From Table 22, it is clear that the results obtained by the proposed research and by the statistical method are quite in agreement with each other. WNC and WSC are ranked first and second, respectively, by both of the methods. Likely, regions M, P, SA, and MA occupied the sixth, seventh, eighth, and ninth position, respectively, as computed by both techniques. However, there is a slight variation in the ranking obtained by regions $\mathrm{NE}, \mathrm{ENC}$, and ESC while comparing both techniques

\section{CONCLUSION}

This study proposes a hybrid technique employing the RSFAS (rough set in a fuzzy approximation space) and FSS (fuzzy soft set) techniques. RSFAS is an extension of the rough set technique, 
Table 17. Tabular representation of fuzzy soft set

\begin{tabular}{|l|l|l|l|l|l|l|l|l|l|l|}
\hline & \multicolumn{1}{|c|}{ CN } & \multicolumn{1}{|c|}{ CD } & \multicolumn{1}{|c|}{ RHS } & \multicolumn{1}{|c|}{ CM } & \multicolumn{1}{|c|}{ CHE } & \multicolumn{1}{|c|}{ QHE } & \multicolumn{1}{|c|}{ CT } & HR & RH \\
\hline NE & 0.993 & 0.947 & 0.943 & 0.967 & 0.96 & 0.777 & 0.976 & 0.939 & 0.957 \\
\hline MA & 0.952 & 0.915 & 0.87 & 0.907 & 0.901 & 0.777 & 0.894 & 0.88 & 0.901 \\
\hline SA & 0.952 & 0.947 & 0.87 & 0.967 & 0.901 & 0.875 & 0.894 & 0.901 & 0.901 \\
\hline ENC & 0.993 & 0.947 & 0.943 & 0.967 & 0.96 & 0.875 & 0.976 & 0.977 & 0.957 \\
\hline ESC & 0.993 & 0.991 & 0.943 & 0.967 & 0.94 & 0.997 & 0.929 & 0.939 & 0.957 \\
\hline WNC & 0.993 & 0.991 & 1 & 0.967 & 1 & 0.958 & 1 & 1 & 1 \\
\hline WSC & 0.993 & 0.991 & 0.943 & 0.967 & 0.96 & 0.997 & 0.976 & 0.977 & 0.957 \\
\hline M & 0.952 & 0.947 & 0.943 & 0.967 & 0.94 & 0.875 & 0.929 & 0.939 & 0.957 \\
\hline P & 0.952 & 0.947 & 0.943 & 0.967 & 0.94 & 0.813 & 0.929 & 0.939 & 0.957 \\
\hline
\end{tabular}

Table 18. Choice value region wise

\begin{tabular}{|l|l|l|l|l|l|l|l|l|l|}
\hline Region & \multicolumn{1}{|c|}{ NE } & \multicolumn{1}{|c|}{ MA } & SA & ENC & ESC & WNC & WSC & M & P \\
\hline $\begin{array}{l}\text { Choice } \\
\text { value }\end{array}$ & 8.459 & 7.997 & 8.208 & 8.595 & 8.656 & 8.909 & 8.761 & 8.449 & 8.387 \\
\hline
\end{tabular}

Table 19. Choice value by region (for 2017 data)

\begin{tabular}{|l|c|c|c|c|c|c|c|c|c|}
\hline \multicolumn{1}{|c|}{ Region } & NE & MA & SA & ENC & ESC & WNC & WSC & M & P \\
\hline Choice value & 8.414 & 8.038 & 8.243 & 8.599 & 8.683 & 8.899 & 8.751 & 8.497 & 8.332 \\
\hline
\end{tabular}

whereas FSS is an extension of the soft set technique. The authors have proposed a model for decision making. The model has been used for ranking the hospitals. This research reflects how computational intelligence techniques - such as rough set and soft set techniques — can be employed for ranking the hospitals. In addition to this, the proposed framework would be more suitable for handling real life problems where the data is quantitative in nature.

Every technique has its limitations. Similarly, the proposed framework cannot suitably process a large volume of data, as the complexity would increase in polynomial time. However, we can address this issue by the discretization of raw data. This research can be carried out further by proceeding in the following directions:

1. In Table 21, we have derived the Hamming distance by region. Of them all, the WNC region has the minimum distance (0.0455), whereas the MA region has the maximum distance (0.5015), from the target set. It signifies that the error associated with WNC is least, while the error associated with MA is highest. In future research, an optimization technique such as a Genetic algorithm can be employed to minimize the error.

2. This paper employs the RSFAS (rough set in a fuzzy approximation space) technique in the first stage. A future research framework, replacing the RSFAS approach with an RSIFAS (a rough set in an intuitionistic fuzzy approximation) technique, can be designed. Similarly, the fuzzy soft set (FSS) approach can be replaced by the intuitionistic fuzzy soft set (IFSS) technique.

3. Future research can also be carried out by using a multi-granulation rough set technique. 


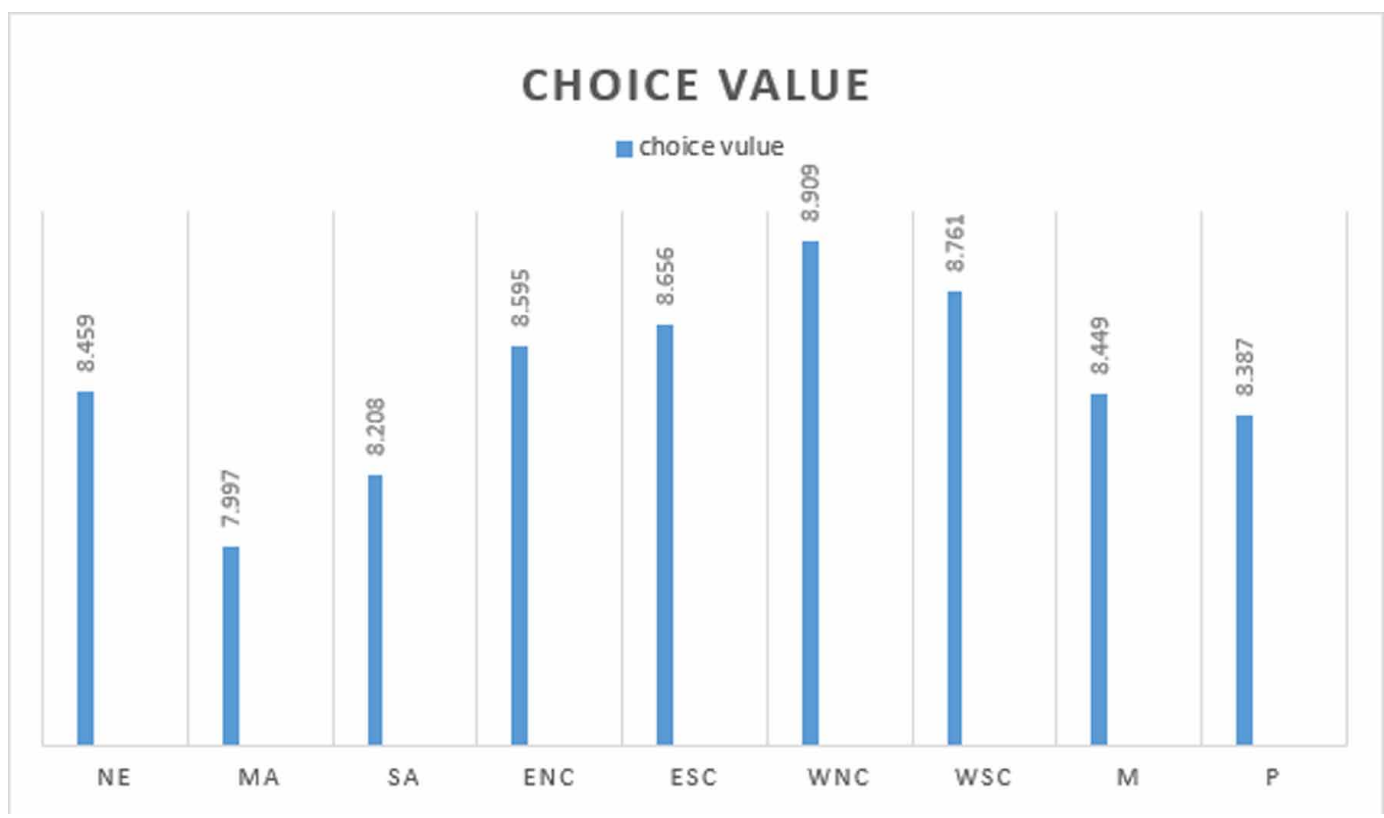

Table 20. Universal fuzzy soft set

\begin{tabular}{|c|c|c|c|c|c|c|c|c|c|}
\hline & CN & CD & RHS & CM & CHE & QHE & CT & HR & RH \\
\hline $\mathrm{NE}$ & 1 & 1 & 1 & 1 & 1 & 1 & 1 & 1 & 1 \\
\hline MA & 1 & 1 & 1 & 1 & 1 & 1 & 1 & 1 & 1 \\
\hline SA & 1 & 1 & 1 & 1 & 1 & 1 & 1 & 1 & 1 \\
\hline ENC & 1 & 1 & 1 & 1 & 1 & 1 & 1 & 1 & 1 \\
\hline ESC & 1 & 1 & 1 & 1 & 1 & 1 & 1 & 1 & 1 \\
\hline WNC & 1 & 1 & 1 & 1 & 1 & 1 & 1 & 1 & 1 \\
\hline WSC & 1 & 1 & 1 & 1 & 1 & 1 & 1 & 1 & 1 \\
\hline M & 1 & 1 & 1 & 1 & 1 & 1 & 1 & 1 & 1 \\
\hline P & 1 & 1 & 1 & 1 & 1 & 1 & 1 & 1 & 1 \\
\hline
\end{tabular}

Table 21. Hamming distance (according to region)

\begin{tabular}{|c|c|c|c|c|c|c|c|c|c|}
\hline Region & NE & MA & SA & ENC & ESC & WNC & WSC & M & P \\
\hline Distance & 0.2705 & 0.5015 & 0.396 & 0.2025 & 0.172 & 0.0455 & 0.1195 & 0.2755 & 0.3065 \\
\hline
\end{tabular}

4. The result obtained through all these techniques can be compared so as to identify the combination most suited to solving the given problem. 
Figure 4. Comparison of choice value (Score) by region

\section{Score by region}

\section{9}

8.8

8.6

8.4

8.2

8

7.8

7.6

7.4
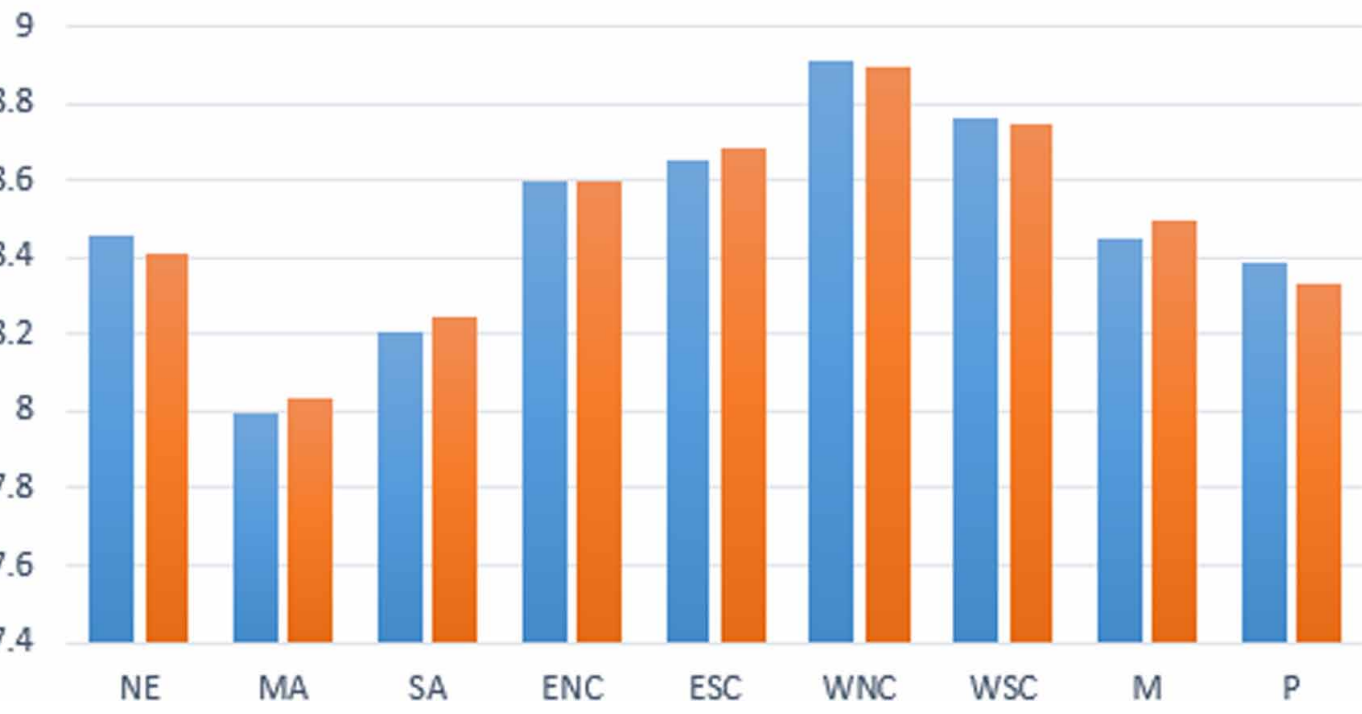

Table 22. Comparative analysis

\begin{tabular}{|l|l|l|l|l|}
\hline \multicolumn{1}{|c|}{ Region } & \multicolumn{2}{c|}{ Proposed Research } & \multicolumn{2}{c|}{ Statistical Technique } \\
\hline & \multicolumn{1}{|c|}{ Choice value } & \multicolumn{1}{c|}{ Rank } & Normalized score & \multicolumn{1}{c|}{ Rank } \\
\hline NE & 8.459 & 5th & 6.826 & 4th \\
\hline MA & 7.997 & 9th & 0.099 & 9 th \\
\hline SA & 8.208 & 8th & 1.76 & 8th \\
\hline ENC & 8.595 & 4th & 7.824 & 3rd \\
\hline ESC & 8.656 & 3rd & 6.65 & 5th \\
\hline WNC & 8.909 & 1st & 10.086 & 1st \\
\hline WSC & 8.761 & 2nd & 8.351 & 2nd \\
\hline M & 8.449 & 6th & 4.369 & 6th \\
\hline P & 8.387 & 7th & 3.372 & 7th \\
\hline
\end{tabular}




\section{REFERENCES}

Acharjya, D. P., \& Das, T. K. (2017). A framework for attribute selection in marketing using rough computing and formal concept analysis. IIMB Management Review, 29(2), 122-135. doi:10.1016/j.iimb.2017.05.002

Akdag, H., Kalayci, T., Karagoz, S., Zulfikar, H., \& Giz, D. (2014). The evaluation of hospital service quality by fuzzy MCDM. Applied Soft Computing, 23, 239-248. doi:10.1016/j.asoc.2014.06.033

Andaleeb, S. S. (2001). Service quality perceptions and patient satisfaction: A study of hospitals in a developing country. Social Science \& Medicine, 52(9), 1359-1370. doi:10.1016/S0277-9536(00)00235-5 PMID:11286361

Austin, J. M., Jha, A. K., Romano, P. S., Singer, S. J., Vogus, T. J., Wachter, R. M., \& Pronovost, P. J. (2015). National hospital ratings systems share few common scores and may generate confusion instead of clarity. Health Affairs, 34(3), 423-430. doi:10.1377/hlthaff.2014.0201 PMID:25732492

Bakar, C., Akgün, H. S., \& Al Assaf, A. L. (2008). The role of expectations in patients' hospital assessments: A Turkish university hospital example. International Journal of Health Care Quality Assurance, 21(5), 503-516. doi:10.1108/09526860810890477 PMID:18785349

Beukers, P. D. C., Kemp, R. G. M., \& Varkevisser, M. (2014). Patient hospital choice for hip replacement: Empirical evidence from the Netherlands. The European Journal of Health Economics, 15(9), 927-936. doi:10.1007/s10198-013-0535-7 PMID:24158316

Beynon, M., Curry, B., \& Morgan, P. (2001). Knowledge discovery in marketing: An approach through rough set theory. European Journal of Marketing, 35(7/8), 915-937. doi:10.1108/EUM0000000005734

Bohm, J. (2013). Relating patient satisfaction to insurance coverage: A Comparison of market based and Government Sponsored health care. Academy of Business Research Journal, 1, 1-11.

Bowers, M. R., \& Kiefe, C. I. (2002). Measuring health-care quality: Comparing and contrasting the medical and the marketing approaches. American Journal of Medical Quality, 17(4), 136-144. doi:10.1177/106286060201700403 PMID:12153066

Buyukozkan, G., Cifci, G., \& Guleryuz, S. (2011). Strategic analysis of healthcare service quality using fuzzy AHP methodology. Expert Systems with Applications, 38(8), 9407-9424. doi:10.1016/j.eswa.2011.01.103

Chia-Wen, C., Ting-Hsiang, T., \& Woodside, A. G. (2013). Configural algorithms of patient satisfaction, participation in diagnostics, and treatment decisions' influences on hospital loyalty. Journal of Services Marketing, 27(2), 91-103. doi:10.1108/08876041311309225

Chowdhary, C. L., \& Acharjya, D. P. (2016). A Hybrid Scheme for Breast Cancer Detection using Intuitionistic Fuzzy Rough Set Technique. International Journal of Healthcare Information Systems and Informatics, 11(2), 38-61. doi:10.4018/IJHISI.2016040103

Chowdhary, C. L., \& Acharjya, D. P. (2017). Clustering Algorithm in Possibilistic Exponential Fuzzy C-Mean Segmenting Medical Images. Journal of Biomimetics, Biomaterials and Biomedical Engineering, 30, 12-23. doi:10.4028/www.scientific.net/JBBBE.30.12

Dagger, T. S., Sweeney, J. C., \& Johnson, L. W. (2007). A hierarchical model of health service quality: Scale development and investigation of an integrated model. Journal of Service Research, 10(2), 123-142. doi: $10.1177 / 1094670507309594$

Das, T. K. (2016). Intelligent Techniques in Decision Making: A Survey. Indian Journal of Science and Technology, 9(12), 1-6. doi:10.17485/ijst/2016/v9i12/86063

Das, T. K. (2016). Multi-criteria Decision Making in Marketing by using Fuzzy Rough set. In A. Kumar et al. (Ed.), Handbook of Research on Intelligent Techniques and Modeling Applications in Marketing Analytics (pp. 100-118). Hershey, PA: IGI Global.

Das, T. K., \& Acharjya, D. P. (2014). A decision making model using soft set and rough set on fuzzy approximation spaces. International Journal of Intelligent Systems Technologies and Applications, 13(3), 170-186. doi:10.1504/ IJISTA.2014.065172 
Das, T. K., Acharjya, D. P., \& Patra, M. R. (2014). Business Intelligence from Online Product Review - A Rough Set Based Rule Induction Approach. In 2014 International Conference on Contemporary computing and informatics, Mysore, India (pp. 800-803). IEEE. doi:10.1109/IC3I.2014.7019662

De, S. K. (1999). Some aspects of fuzzy sets, rough sets and intuitionistic fuzzy sets [Ph.D. Thesis]. IIT, Kharagpur, India.

Dean, A. M. (1999). The applicability of SERVQUAL in different health care environments. Health Marketing Quarterly, 16(3), 1-21. doi:10.1300/J026v16n03_01 PMID:10538736

Devebakan, N. (2005). Sag?lik Is_letmelerinde Algilanan Hizmet kalitesi ve Ölçümü. Sag?lik Bilimleri Enstitüsü. Izmir: Dokuz Eylül Üniversitesi.

Devebakan, N., \& Aksarayli, M. (2003). Sag?lik Is_letmelerinde Algilanan Hizmet Kalitesinin Ölçümünde SERVQUAL Skorlarinin Kullanimi ve Özel Altinordu

Gremler, D. D., Gwinner, K. P., \& Brown, S. W. (2001). Generating positive word-of-mouth communication through consumer-employee relationships. International Journal of Service Industry Management, 12(1), 44-59. doi:10.1108/09564230110382763

Handayani, P. W., Hidayanto, A. N., Sandhyaduhita, P. I., Kasiyah, , \& Ayuningtyas, D. (2015). Strategic hospital services quality analysis in Indonesia. Expert Systems with Applications, 42(6), 3067-3078. doi:10.1016/j. eswa.2014.11.065

Kumar, V., Smart, P. A., Maddern, H., \& Maull, R. S. (2008). Alternative perspective on service quality and Customer satisfaction: The role of BPM. International Journal of Service Industry Management, 19(2), 25-35. doi: $10.1108 / 09564230810869720$

Ladhari, R. (2009). A review of twenty years of SERVQUAL research. International Journal of Quality and Service Sciences, 1(2), 172-198. doi:10.1108/17566690910971445

Lee, H., Lee, Y., \& Yoo, D. (2000). The determinants of perceived service quality and its relationship with satisfaction. Journal of Services Marketing, 14(3), 217-231. doi:10.1108/08876040010327220

Lee, M. A., \& Yom, Y. H. (2007). A comparative study of patients' and nurses' perceptions of the quality of nursing services, satisfaction and intent to revisit the hospital: A questionnaire survey. International Journal of Nursing Studies, 44(4), 545-555. doi:10.1016/j.ijnurstu.2006.03.006 PMID:16687147

Lee, S., Lee, D. H., \& Kang, C.-Y. (2012). The impact of high-performance work systems in the health-care industry: Employee reactions, service quality, customer satisfaction, and customer loyalty. Service Industries Journal, 32(1), 17-36. doi:10.1080/02642069.2010.545397

$\mathrm{Li}$, L. (1997). Relationships between determinants of hospital quality management and service quality performance - A path analytic model. Omega, 25(5), 535-545. doi:10.1016/S0305-0483(97)00017-0

Li, M., Lowrie, D. B., Huang, C. T., Lu, X. C., Zhu, Y. C., Wu, X. H., \& Lu, H. Z. et al. (2015). Evaluating patient's perception of service quality at hospitals in nine Chinese cities by use of the SERVQUAL scale. Asian Pacific Journal of Tropical Biomedicine, 5(6), 497-504. doi:10.1016/j.apjtb.2015.02.003

Lupo, T. (2016). A fuzzy framework to evaluate service quality in the healthcare industry: An empirical case of public hospital service evaluation in Sicily. Applied Soft Computing, 40, 468-478. doi:10.1016/j.asoc.2015.12.010

Maji, P. K., Biswas, R., \& Roy, A. R. (2003). Soft set theory. Computers \& Mathematics with Applications (Oxford, England), 45(4-5), 555-562. doi:10.1016/S0898-1221(03)00016-6

Maji, P. K., Roy, A. R., \& Biswas, R. (2002). An application of soft sets in a decision making problem. Computers \& Mathematics with Applications (Oxford, England), 44(8-9), 1077-1083. doi:10.1016/S0898-1221(02)00216-X

Meesala, A., \& Paul, J. (2018). Service quality, consumer satisfaction and loyalty in hospitals: Thinking for the future. Journal of Retailing and Consumer Services, 40, 261-269. doi:10.1016/j.jretconser.2016.10.011

Molodtsov, D. (1999). Soft set theory - first results. Computers \& Mathematics with Applications (Oxford, England), 37(4-5), 19-31. doi:10.1016/S0898-1221(99)00056-5 
Pakdil, F., \& Harwood, T. N. (2005). Patient satisfaction in a preoperative assessment clinic: An analysis using SERVQUAL dimensions. Total Quality Management \& Business Excellence, 16(1), 15-30. doi:10.1080/1478336042000255622

Parasuraman, A., Zeithamal, V., \& Berry, L. (1985). A conceptual model of service quality and its implications for future research. Journal of Marketing, 49(4), 41-50. doi:10.1177/002224298504900403

Parasuraman, A., Zeithamal, V., \& Berry, L. (1988). SERVQUAL - a multiple item scale for measuring consumer perceptions of service quality. Journal of Retailing, 64(1), 12-40.

Pawlak, Z. (1982). Rough sets. International Journal of Computer Information Science, 11(5), 341-356. doi:10.1007/BF01001956

Prabhakar Kalepu, R. N. (2014). Service quality in healthcare sector: An exploratory study on Hospitals. IUP Journal of Marketing Management, 13(1), 7-28.

Radwin, L. (2000). Oncology patients' perceptions of quality nursing care. Res. J. Nurs. Health, 23(3), 179-190. doi:10.1002/1098-240X(200006)23:3<179::AID-NUR2>3.0.CO;2-T PMID:10871533

Ramsaran-Fowdar, R. R. (2008). The relative importance of service dimensions in a healthcare setting. International Journal of Health Care Quality Assurance, 21(1), 104-124. doi:10.1108/09526860810841192 PMID:18437943

Rothberg, M. B., Morsi, E., Benjamin, E. M., Pekow, P. S., \& Lindehauer, P. K. (2008). Choosing the best hospital: The limitations of public quality reporting. Health Affairs, 27(6), 1680-1687. doi:10.1377/hlthaff.27.6.1680 PMID:18997226

Wisniewski, M., \& Wisniewski, H. (2005). Measuring service quality in a hospital colposcopy clinic. International Journal of Health Care Quality Assurance, 18(3), 217-228. doi:10.1108/09526860510594776 PMID:15974517

Wu, C., Yue, Y., Li, M., \& Adjei, O. (2004). The rough set theory and applications. Engineering Computations, 21(5), 488-511. doi:10.1108/02644400410545092

Zadeh, L. A. (1965). A Fuzzy sets. Information and Control, 8(3), 338-353. doi:10.1016/S0019-9958(65)90241-X 